\title{
Isolation, Characterization, Proliferation and Differentiation of Synovial Membrane-derived Mesenchymal Stem Cells (SM-MSCs) from Osteoarthritis Patients
}

\author{
Marlina ${ }^{1}$, Rizki Rahmadian ${ }^{1}$, Armenia $^{1}$, Wahyu Widowati², Rizal ${ }^{3}$, Hanna Sari Widya Kusuma ${ }^{3}$, \\ Satrio Haryo Benowo Wibowo ${ }^{3}$, Wahyu Setia Widodo ${ }^{3}$, Ika Adhani Sholihah ${ }^{3}$ \\ ${ }^{1}$ Faculty of Pharmacy, Andalas University, Padang, Indonesia \\ ${ }^{2}$ Medical Research Center, Faculty of Medicine, Maranatha Christian University, Bandung, Indonesia \\ ${ }^{3}$ Biomolecular and Biomedical Research Centre, Aretha Medika Utama, Bandung, Indonesia
}

Background: Mesenchymal stem cells (MSCs) are the cells which have high renewal capacity and and are capable for differentiating into some types of cells. MSCs can be obtained from several tissues including bone marrow, synovial membrane, blood, adipose tissue and periosteum. The proliferation and self-repair ability of MSCs are the advantages to use as stem cells-based therapy of various diseases. The aim of this study was to determine the differentiation, characterization and proliferation of synovial membrane-derived MSCs (SM-MSCs).

Materials and Methods: The cells proliferation capacity was determined by cell counting using trypan blue, characterization of MSCs (cluster of differentiation (CD)90, CD11b, CD73, CD34, CD19, CD45, CD105 and human leukocyte antigen-DR isotype (HLA-DR)) using flow cytometry analysis, and differentiation capability into three lineage cells was determined with red alcian blue, oil red $\mathrm{O}$ and alizarin staining.

Results: The type culture of SM-MSCs was adherent and showed positive CD44, CD105, CD73, CD90 and negative of CD19, HLA-DR, CD11b, CD45, CD34 surface marker. Based on the result, SM-MSCs P3 showed differentiation potency into adipogenic, chondrogenic, and osteogenic lineage cells. The population doubling time of SM-MSCs has increased from P3 to P8. The population doubling time of SM-MSCs P3 was 1.69 days and SM-MSCs P8 was 3.64 days.

Conclusion: The results indicated that SM-MCSCs from osteoarthritis patients are able to differentiate into osteocytes, chondrocytes, adipocytes and highly express of CD105, CD73, CD90, CD44 and negative for CD34, CD45, CD14, CD19.

Keywords: synovial membrane, mesenchymal stromal cells, adipocyte, chondrocyte, osteocyte

\section{Introduction}

Osteoarthritis (OA) is the most common disease in the joints associated with disability and pain. ${ }^{1}$ The prevalence of OA increases due to aging and an increase in related factors such as obesity. Radiographic evidence of knee OA is present in about $30 \%$ of men and women over the age of 65 years. Estimates around the world are that $9.6 \%$ of men and $18.0 \%$

Date of submission: July 16, 2019

Last Revised: August 21, 2019

Accepted for publication: August 23, 2019

Cell and

Biopharmaceutical Institute 
of women over the age of 60 have symptomatic OA. About $80 \%$ of those with OA will have limitations in movement, and $25 \%$ cannot carry out their daily activities., ${ }^{2,3} \mathrm{OA}$ is one of degenerative diseases in old age population. The disease damage joints and bones around it, and leading to chronic disability. ${ }^{4}$ The main target of $\mathrm{OA}$ is cartilage tissue, and the starting point for $\mathrm{OA}$ is cartilage damage or loss. ${ }^{5}$ The rate of chondrocytes regeneration as the component of cartilage tissue was decreased in older people ${ }^{6}$, as a result, therapy is needed to cure OA. Unfortunately, the existing OA therapy has been used drugs administration and surgery for total joint replacement. ${ }^{7}$ This therapy is not effective because long-term drug administration causes negative effects on the other organs such as cardiovascular, kidneys, and digestive system. ${ }^{8,9}$ Consequently, an alternative therapy is necessary to regenerate damaged articular cartilage.

Chondrocytes are the main cellular component of cartilage, which is widely used for OA treatment.Autologous chondrocytes implantation (ACI) is a biomedical treatment cell-based for OA patients, the procedure takes place in three stages including cartilage isolation, cell grown in vitro and cell implantation to patient. ${ }^{10}$ But this therapy still has various disadvantages, for example surgery that causes cartilage damage, dedifferentiation in chondrocytes and has lower regeneration potency. ${ }^{11}$ Therefore, another approach is required for regeneration of cartilage in OA patients.

Stem cells can be used in tissue regeneration, for stem cells have the ability to differentiate and self-renew at the time of embryonic stage, in which cells can proliferate into tissue or certain organs during the developmental process. ${ }^{12}$ Mesenchymal stem cells (MSCs) can differentiate into adipocytes, chondrocytes and osteocytes. ${ }^{13,14}$ MSCs can be isolated from various sources such as bone marrow (BMMSCs), adipose tissues (AT-MSCs), umbilical cords (UCMSCs), Wharton's jelly (WJ-MSCs), synovial tissues (STMSCs), and other tissues. ${ }^{15,16}$

MSCs isolated from synovial membrane (SM) have ability to differentiate into chondrocytes that very suitable for cartilage regeneration therapy. MSCs are able to fuse with cartilage defects, proliferate, regenerate articular cartilage, reduce the concentration of synovial fluid from prostaglandin ${ }^{17}$ and reduce the progressiveness of OA. ${ }^{18}$ Future research should be directed at addressing the gap in diagnostics and therapy for OA. Hence, research on the potential of SM from OA patients in its use as autologous therapy necessary to be done. The objective of this study was to determine the character, differentiation and proliferation of synovial cells of membranes P4 and P8 isolated from patients with OA.

\section{Materials and methods}

\section{MSCs Isolation from SM}

SMs were obtained from three knee in patients with OA from Dr. M. Djamil Hospital, Padang, Indonesia. The patients have signed the informed consent using the guidelines approved by Research Ethics Committee, Faculty of Medicine, Universitas Andalas, Padang, Indonesia (No. 226/ $\mathrm{KEP} / \mathrm{FK} / 2019$ ). SMs then washed using phosphate buffer saline (PBS) (Catalogue \#14200075, Gibco, Massachusetts, USA), $1 \%$ antibiotic and antimycotic (ABAM) (Catalogue \#15240062, Gibco) and 1\% Amphotericin B (Catalogue \#15290026, Gibco). SMs were cut into small pieces and washed, cleased from skin and fat. The synovial membranes were put into centrifuge tube (Catalogue \#50015, SPL, Pocheon, South Korea) containing Collagenase enzyme type I (Catalogue \#17100017, Gibco), Hyaluronidase (Catalogue \#H-3506, Sigma Aldrich, Massachusetts, USA) and TrypsinEDTA $0.1 \%$ (Catalogue \#25200072, Gibco). The tube stored in $\mathrm{CO}_{2}$ resistant shaker (Catalogue \#SHKE2000CO, Thermo Fisher Scientific, Massachusetts, USA) at $300 \mathrm{rpm}$ for 16 hours in the incubator (Catalogue $\# 8000 \mathrm{DH}$, Thermo Fisher Scientific) of $5 \% \mathrm{CO}_{2}$ and $37^{\circ} \mathrm{C} .{ }^{16}$ The remaining SM was removed, and the supernatant was centrifuged (MPW-260R, Warsaw, Poland) at $1600 \mathrm{rpm}$ for 5 minutes. The supernatant was removed, and the pellet was mixed with complete medium: Mem- $\alpha$ (Catalogue \#32561037, Gibco) which supplemented by $10 \%$ Fetal Bovine Serum (FBS) (Catalogue \#10270106, Gibco), and 1\% ABAM, $1 \%$ Amphotericin B addition. SM-MSCs was cultured at density of $2 \times 10^{6}$ cells in T-flask $25 \mathrm{~cm}^{2}$ (Catalogue \#90026, TPP, Trasadingen, Switzerland). The cells were incubated on T-flask $25 \mathrm{~cm}^{3}$ at $5 \% \mathrm{CO}_{2}$ and $37^{\circ} \mathrm{C}$ incubator. ${ }^{19}$

\section{SM-MSCs Surface Markers Characterization}

The SM-MSCs reached $80 \%$ confluence were harvested for analyzing the positive and negative cluster differentiation (CD) markers (Fowcytometry analyzer 10, Macsquant, California, USA). The cells were stained with hMSCs analysis kit (Caltalogue\#562245, BD stem flowTM Kit, New Jersey, USA) and the procedure was according to the manufacture protocol. The experiments and measurement were performed in triplicate. ${ }^{18,20}$ 


\section{Differentiation Capability of SM-MSCs}

The osteogenic differentiation, SM-MSCs (P4 and P8) were seeded at density $5 \times 10^{3}$ in 24 well plate (Catalogue $\# 142475$, Nunc, Massachusetts, USA) using StemPro Osteogenesis Differentiation Kit (Catalogue \#A10072-01, Gibco) for 3 weeks. Osteocytes were visualized using Alizarin Red S (Catalogue \#A5533, Sigma Aldrich).

The chondrogenic differentiation, SM-MSCs (P4, P8) were seeded $5 \times 10^{3}$ cells 24 well plate using StemPro Chondrogenesis Differentiation Kit (Catalogue\# A1007101, Gibco) for 3 weeks. Chondrocytes were confirmed using Alcian blue (Catalogue\#A5268, Sigma Aldrich).

Adipogenic differentiation of SM-MSCs was executed by StemPro Adipogenic Differentiation Kit (Catalogue \#A10070-01, Gibco) for 3 weeks. To confrim lipid droplets in the culture as the marker of adiponic differentiation using Oil Red O staining (Catalogue \#00625, Sigma Aldrich). ${ }^{13,21}$

\section{Population Doubling (PD) Time of SM-MSCS}

P4-P8 of SM-MSCs in T75 flask were detached by $3 \mathrm{~mL}$ of trypsin-EDTA $0.25 \%$ (Catalogue \#25200072, Gibco) and was incubated at $5 \% \mathrm{CO}_{2}$ and $37^{\circ} \mathrm{C}$ incubator for 3 minutes. The complete medium was added to stop the trypsin and the cells were centrifugated at $1600 \mathrm{rpm}$ for 5 minutes. The obtained pellet was added with $1 \mathrm{~mL}$ complete medium. The cells were counted by a hemocytometer (Catalogue \#17849, Neubauer, Lauda-Königshofen, Germany) using 1:1 Trypan Blue (Catalogue \#T8154, Sigma Aldrich) as the stain. PD was counted at every passage with formula: $\mathrm{PD}=$ LOG (Harvest/Seeded)/ $\mathrm{LOG}_{2}{ }^{22}$ Meanwhile, the PD time (PDT) was determined by this formula: $\mathrm{PDT}=\mathrm{t}$ (time) $/ \mathrm{PD}$ (in days). ${ }^{18}$

\section{Statistical Analysis}

Statistical was analyzed with Statistical Package for the Social Sciences (SPSS) statistics version 20.0 software (IBM Corporation, New York, USA). Value was provided as mean \pm standard deviation. Significant diversity between the groups were determined using the analysis of variance (One Way ANOVA) followed by Tukey's HSD Post-hoc test.

\section{Results}

\section{SM-MSCs Characteristic}

Figure 1 showed the culture SM-MSCs at P4 as the result of cells isolation from OA patients. SM-MSCs exhibited adherent of culture, resulted, and elongated in spindle- shaped cells. SM-MSCs exhibited adherent type of culture, elongated and resulted in spindle-shaped cells. In Figure 2 and Table 1, SM-MSCs that was isolated from OA patients at $\mathrm{P} 4$ and $\mathrm{P} 8$ showed negative expression for $\mathrm{CD} 34, \mathrm{CD} 11 \mathrm{~b}$, CD45, CD19 and HLA-DR, yet showed high expression for CD44, CD90, CD73 and CD105. The two different passages, P4 (early) and P8 (intermediate) of the cells showed no difference CD markers expression. Both P4 and P8 were detected to have the same level expression of certain positive and negative surface markers.

\section{Differentiation of MSCs}

The result of SM-MSCs differentiation into 3 different types of cells. They were chondrocyte, adipocyte, and osteocyte as shown in Figure 3. There was no difference result of differentiation between P4 and P8 from the qualitative staining result. Osteogenic showed positive result by the red color and confirmed by the accumulation of calcium deposit which detected by Alizarin Red S. Glycosaminoglycan as well as the marker of chondrogenesis could be identified with Alcian Blue staining as specific polyvalent dye that was used to identify acidic polysaccharides. As can be seen in the Figure 3, the cells were associated in the process of chondrogenic differentiation and stained as blackish blue. Oil Red $\mathrm{O}$ was used as a dye in adipogenic differentiation which was characterized by the formation of oil droplets. Oil Red O was a diazo dye that was used to stain the lipid formation and triglycerides. ${ }^{10,19,20,22}$

\section{PDT of SM-MSCS}

PDT and cumulative population doubling (CPD) data were shown in Table 2. SM-MSCs isolated from the synovial

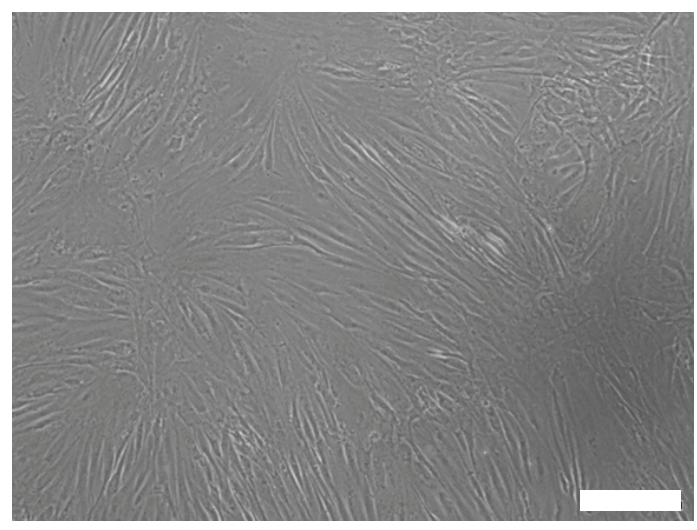

Figure 1. P4 of SM-MSCs culture with adherent characteristic . White bar: $200 \mu \mathrm{m}$. 

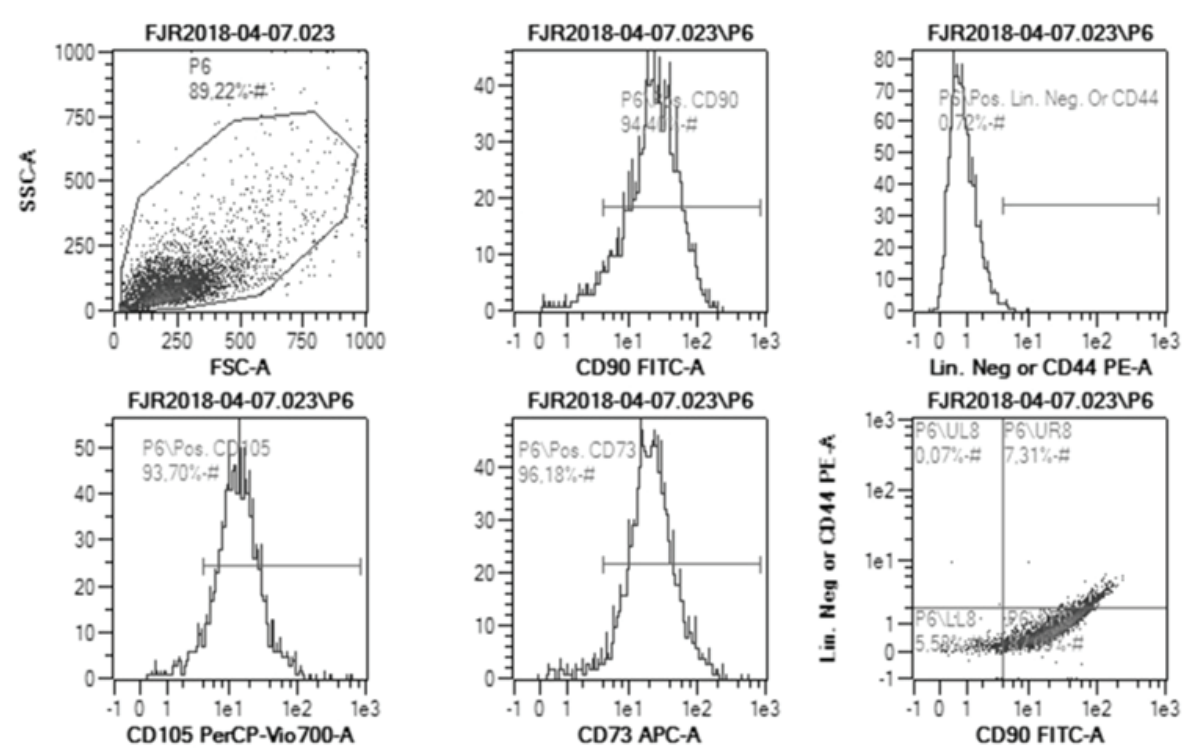

\begin{tabular}{|c|c|c|c|c|c|}
\hline \multirow{2}{*}{$\begin{array}{l}\text { File } \\
\text { SID }\end{array}$} & FJR2018-04-07.023 mad & \multicolumn{4}{|l|}{ 2018-Apr-07 16:16 } \\
\hline & Moxcocktal - 1 & Descr. & & & \\
\hline \multicolumn{2}{|c|}{ Path } & $\%-H$ & Count & Count/mL & Count $/ \mu \mathrm{L}$ \\
\hline \multirow{5}{*}{\multicolumn{2}{|c|}{$\begin{array}{l}\text { FJR2018-04-07.023 } \\
\text { PG Pos. CD } 90 \\
\text { PG Pos. Lin. Neg. OrCD } 44 \\
\text { PG Pos. CD } 105 \\
\text { PG Pos. CD } 73\end{array}$}} & - & 4664 & $1,74 \mathrm{e} 5$ & 173.95 \\
\hline & & 94.40 & 3928 & $1.46 \mathrm{e} 5$ & 146.50 \\
\hline & & 0.72 & 30 & $1.12 \mathrm{e} 3$ & 1.12 \\
\hline & & 93.70 & 3899 & $1.45 \mathrm{e} 5$ & 145.41 \\
\hline & & 96.18 & 4002 & $1,49 \mathrm{e} 5$ & 149.26 \\
\hline
\end{tabular}
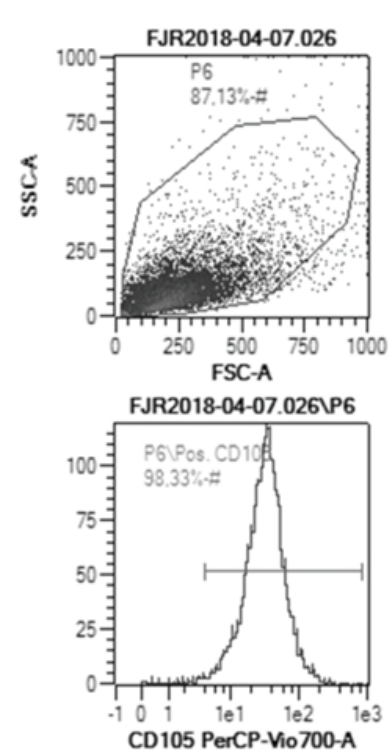
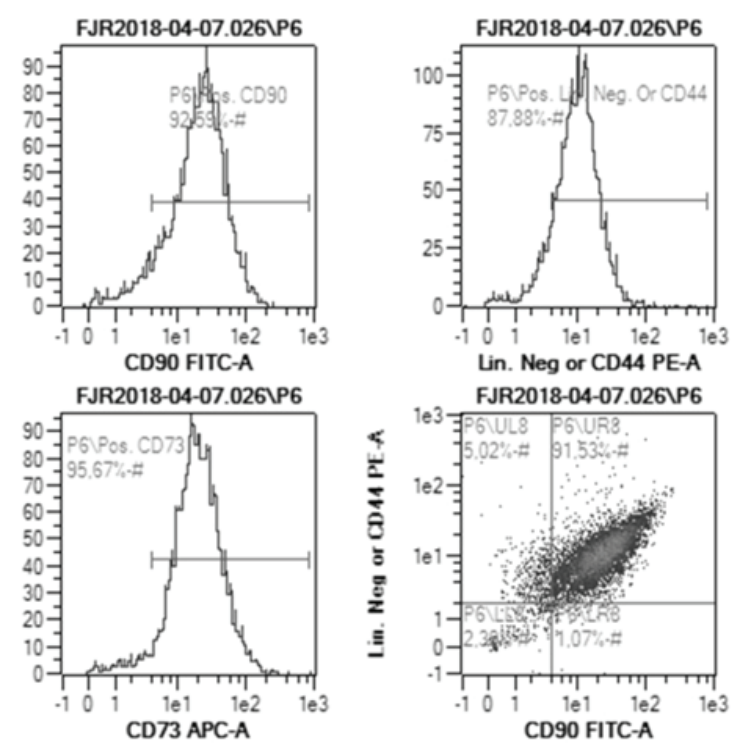

$\begin{array}{lll}\text { File } & \text { FJR2018-04-07.026 mad } & \text { 2018-Apr-07 16:23 } \\ \text { SID } & \text { Moccocktal +PE - } 1 & \text { Descr. }\end{array}$

\begin{tabular}{|c|c|c|c|c|}
\hline Path & $\%-\#$ & Count & Count/mL & Count $/ \mu \mathrm{L}$ \\
\hline $\begin{array}{l}\text { FJR2018-04.07.026 } \\
\text { PG Pos. CD } 90 \\
\text { PG Pos. Lin. Neg. Or CD } 44 \\
\text { PG Pos. CD } 105 \\
\text { PG Pos. CD } 73\end{array}$ & $\begin{array}{r}92 . \overline{59} \\
87.88 \\
98.33 \\
95.67\end{array}$ & $\begin{array}{r}10321 \\
8327 \\
7903 \\
8843 \\
8604\end{array}$ & $\begin{array}{l}2.06 \mathrm{e} 5 \\
1,67 \mathrm{e} 5 \\
1.58 \mathrm{e} 5 \\
1,77 \mathrm{e} 5 \\
1,72 \mathrm{e} 5\end{array}$ & $\begin{array}{l}206.42 \\
166.54 \\
158.06 \\
176.86 \\
172.08\end{array}$ \\
\hline
\end{tabular}

Figure 2. The dot blot expression marker of SMMSCs analyzed by flow cytometer. SM-MSCs was confirmed as MSCs with high expression for positive marker, CD90: 92.59\%; CD73: 95.67\%, and CD105: $98.33 \%$. MSCs also low expression of negative lineage. SM-MSCs also exhibited positive expression for CD44 as the additional $\mathrm{CD}$ markers to define MSCs. 
Table 1. The different eggect of passages toward surface markers of SM-MSCs.

\begin{tabular}{cccccc}
\hline Passage & CD90 & CD44 & CD105 & CD73 & $\begin{array}{c}\text { Negative } \\
\text { Lineage }\end{array}$ \\
\hline P4 & $92.52 \pm 0.15$ & $87.02 \pm 0.58$ & $98.34 \pm 0.02$ & $95.15 \pm 0.59$ & $0.42 \pm 0.18$ \\
P8 & $92.59 \pm 0.11$ & $87.88 \pm 0.49$ & $98.33 \pm 0.02$ & $95.67 \pm 0.42$ & $0.72 \pm 0.18$ \\
\hline
\end{tabular}

Data are presented as mean \pm standard deviation of surface markers of SM-MSCs. Negative lineage marker containing CD45, CD34, CD11b, CD19 and HLA-DR.

shows that PDT and CPD increase along with the increase of passage and was significantly different among the passages except the $5^{\text {th }}$ and the $6^{\text {th }}$ passage were defined as not significantly different at $p<0.05$. The PDT and CPD can be seen in Table 2 and were used to measure the MSCs proliferation capacity and define as a specific time for cells to undergo the cell division. PDT from P3-P8 was ranged 1.69 to 3.64 days.

\section{Discussion}

SM-MSCs from the knee of OA patient with grade IV are used because they are waste that is not used anymore. OA patient with grade IV has low quality of stemness, MSCs quantity and quality decrease with aging, limiting the potential efficacy of MSCs for therapy the elderly population. ${ }^{21}$ We try to develop method by utilizing waste materials and low quality. There are 3 basic criteria of the cells to be characterized as MSCs based on the International Society for Cellular Therapy, such as: 1) have differentiation capability into osteocyte, adipocyte, and chondrocyte; 2)

Table 2. PDT and CPD of SM-MSCs.

\begin{tabular}{|c|c|c|}
\hline Passage & PDT (d) & CPD \\
\hline P3 & $1.69 \pm 0.04^{\mathrm{a}}$ & 1.69 \\
\hline P4 & $1.79 \pm 0.02^{\mathrm{b}}$ & 3.46 \\
\hline P5 & $2.36 \pm 0.03^{\mathrm{c}}$ & 5.82 \\
\hline P6 & $2.33 \pm 0.03^{\mathrm{c}}$ & 8.15 \\
\hline $\mathrm{P} 7$ & $3.15 \pm 0.01^{\mathrm{d}}$ & 11.3 \\
\hline P8 & $3.64 \pm 0.03^{\mathrm{e}}$ & 14.94 \\
\hline $\begin{array}{l}\text { Data were } \\
\text { deviation. I } \\
\text { in the same } \\
\text { (Tukey HSD }\end{array}$ & $\begin{array}{l}\text { esented a } \\
\text { ent small } \\
\text { Imn are si } \\
\text { hoc test). }\end{array}$ & $\begin{array}{r}\text { an } \pm \text { sta } \\
(\mathrm{a}, \mathrm{b} \\
\text { t at } p\end{array}$ \\
\hline
\end{tabular}

have the adherent type of culture; 3 ) have positive expression for several CD markers such as CD44, CD73, CD90, and CD105 and showed negative expression for CD45, CD14, CD34, and HLA-DR. ${ }^{21-24}$ Markers characterization of the cells results in same finding with the previous study showed that the MSCs isolated different sources was also showed high expression of CD73, CD44, CD90, CD105 and low expression of CD19, CD45, CD34, CD14 and HLA-II both early (P4) and intermediate passage (P8)..$^{13,22,25}$ It also appropriate with previous study that MSCs from various sources, such as AT-MSCs had positive markers for CD90, CD73, and CD105. AT-MSCs had negative markers of CD14 or CD11b, CD34, CD19, CD45, and HLA-DR in their cellsurface immunophenotyped. Several studies also proved that MSCs have positive surface marker of CD44... ${ }^{22,26,27}$ The cells isolated from SM of OA patients also conformed with previous study which SM-MSCs had positive CD44. ${ }^{26}$

According to the results, the cells isolated from the SM was considered as MSCs be able to differentiate into 3 types of cells (osteocyte, chondrocyte, adipocyte). Thus, the method has succesfully used to produce SM-MSCs and considered as the first step of application mediated therapy for OA patiens.

The PDT and CPD difference in the $5^{\text {th }}$ and the $6^{\text {th }}$ passage might caused by the proliferation capacity of cells were decreased at the higher passage. As indicated by MSCs derived from other sources such as BM-MSCs and AT-MSCs have relative shorter culture time, the cell growth was slower at P10-P11, at P14-P16 in umbilical cord blood MSCs (UCB-MSCs). ${ }^{28}$ The PDT result are supported by previous research which explained that WJ-MSCs induced by normoxia and hypoxia $2,5 \%$ and $5 \%$ have increase in proliferation time from early passage to older passage..$^{22}$ The validation SM-MSCs from various grade OA patients is needed to confirm the isolation and characterization method. The validation of SM-MSCs for OA therapy in animal is needed to continue models should eventually follow for further study. 


\section{A. Differentiation of SM-MSCs}
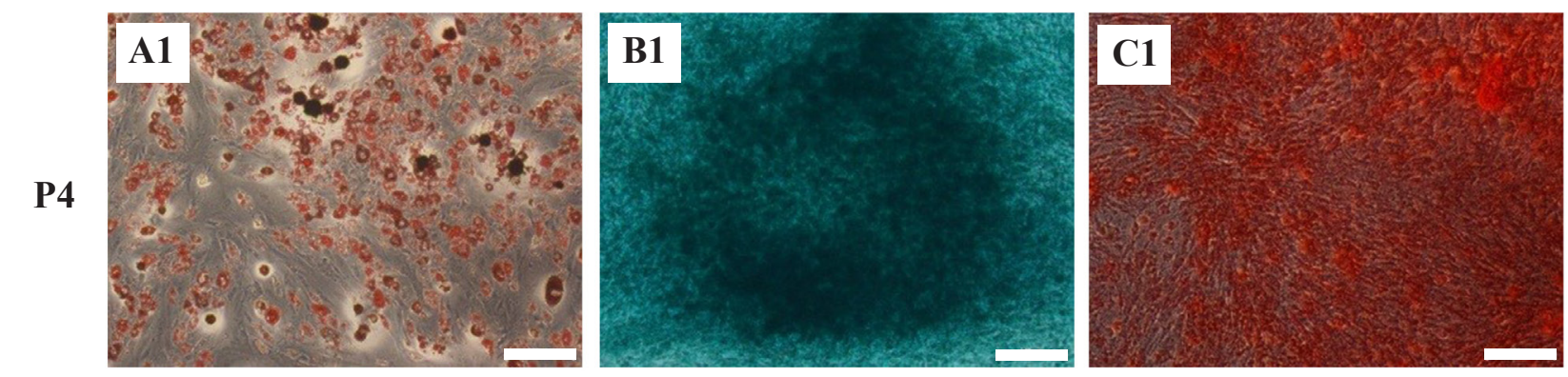

P8
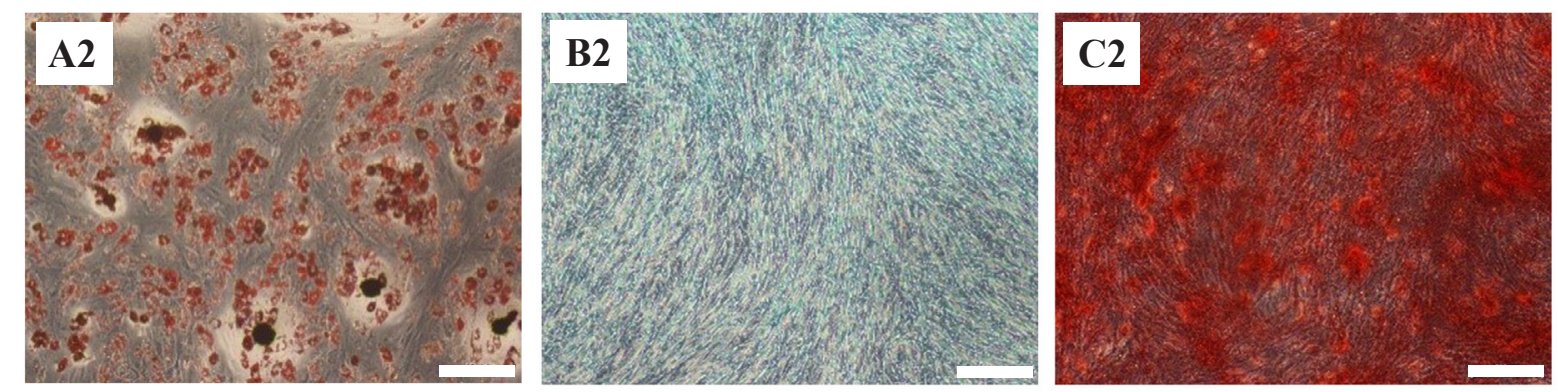

\section{B. Negative Control}
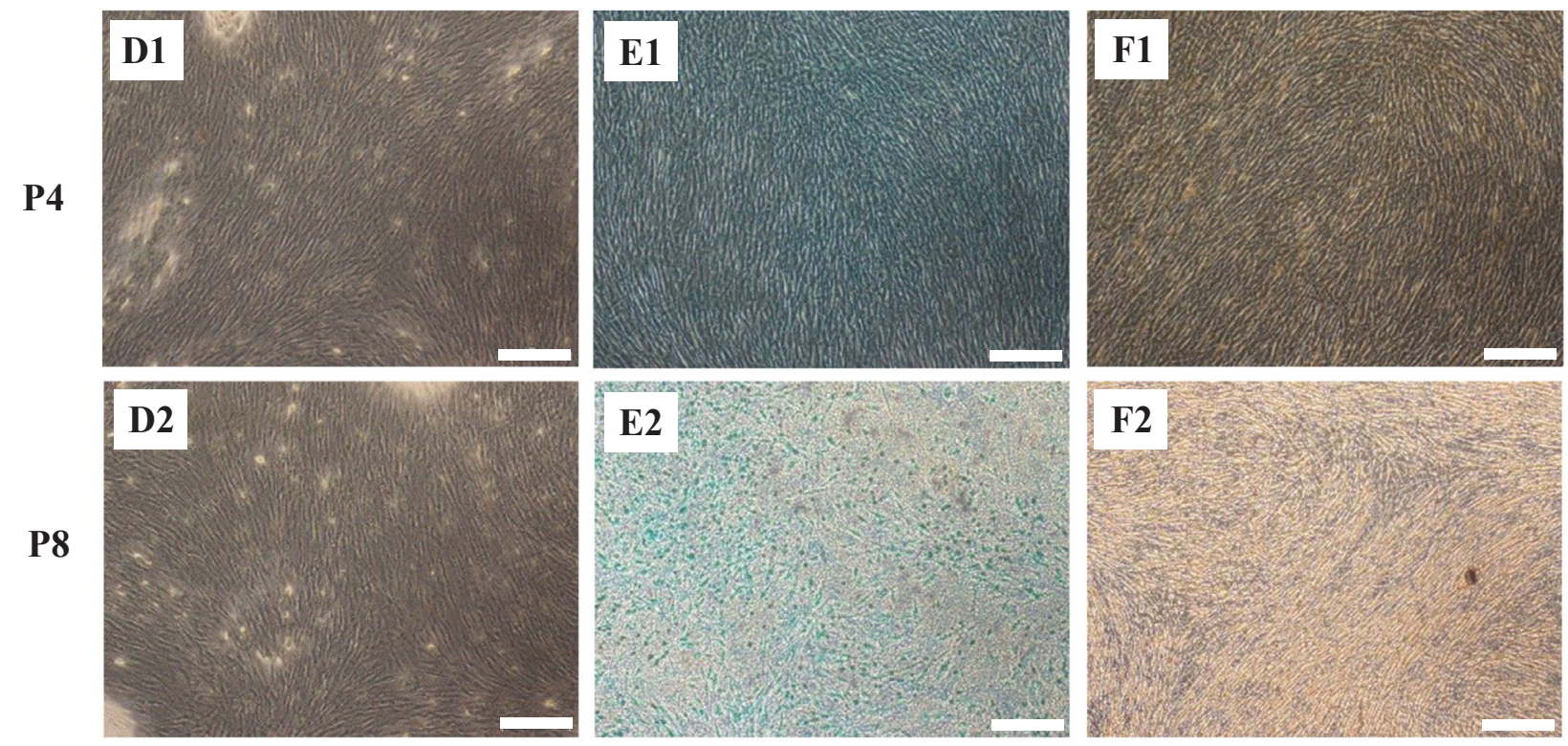

Figure 3. Morphology analysis of osteogenic, chondrogenic, adipogenic differentiation of SM-MSCs at P4 and P8. A1: Differentiation adipocytes P4; A2: Differentiation adipocytes P8; B1: Differentiation chondrocytes P4; B2: Differentiation chondrocytes P8; C1: Differentiation osteocytes P4; C2: Differentiation osteocytes P8; D1: Control adipocytes P4; D2: Control adipocytes P8; E1: Control chondrocytes P4; E2: Control chondrocytes P8; F1: Control osteocytes P4; F2: Control osteocytes P8.

\section{Conclusion}

The results of this experiment indicated that SMMSCs isolated from OA patients has been successfully characterized. SM-MSCs have high expression of CD90,
CD44, CD105, CD73 and low expression of CD34, CD45, CD14, CD19, HLA-II, be able to differentiate into osteocyte, chondrocyte, adipocyte and have the adherent type of culture. 


\section{Acknowledgements}

The research was funded by Ministry of Reseach, Tecnology, and Higher Education of the Republic Indonesia (Research Grant Hibat Kompetensi). This research was supported also by Grant Professor from Andalas University and research facilities, methodology supported by Aretha Medika Utama Biomolecular and Biomedical Research Center (AMUBBRC), Bandung, Indonesia. The authors also would like to thank to Dwi Surya Artie, Dewani Tediana Yusepany, Anisa Siwianti from AMU-BBRC for their valuable assistance.

\section{References}

1. Loeser RF, Goldring SR, Scanzello CR, Goldring MB. Osteoarthritis: a disease of the joint as an organ. Arthritis Rheum. 2012; 64(6): 1697-707.

2. Teitel AD, Zieve D. Medline Plus Medical Encycolpedia: Osteoarthritis. Bethesda: National Institutes of Health; 2011.

3. World Health Organization [Internet]. Chronic diseases and health promotion: chronic rheumatic conditions [updated 2012; cited 2019 Mar 30]. Available from: https://www.who.int/chp/topics/ rheumatic/en/.

4. Ahmed U, Anwar A, Savage RS, Costa ML, Mackay N, Filer A, et al. Biomarkers of early stage osteoarthritis, rheumatoid Arthritis and Musculoskeletal Health. Sci Rep. 2015; 5: 9259. doi: 10.1038/ srep09259.

5. Brandt, KD. Non-surgical treatment of osteoarthritis: a half century of "dvances". Ann Rheum Dis. 2004; 63(2): 117-22.

6. Khairani Y, Eryasni H, Nindya A. Hubungan Umur, Jenis Kelamin, IMT, dan Aktivitas Fisik Dengan Kejadian Osteoathritis Lutut. Jambi: Fakultas Kedokteran dan Ilmu Kesehatan Universitas Jambi; 2013.

7. Gabriel SE. The epidemiology of rheumatoid arthritis. Rheum Dis Clin North Am. 2001; 27(2): 269-81.

8. Kremers HM, Nicola P, Crowson CS, O'Fallon WM, Gabriel SE. Therapeutic strategies in rheumatoid arthritis over a 40-year period. J Rheumatol. 2004; 31(12): 2366-73.

9. Leong DJ, Choudhury M, Hanstein R, Hirsh DM, Kim SJ, Majeska $\mathrm{RJ}$, et al. Green tea polyphenol treatment is chondroprotective, antiinflammatory and palliative in a mouse post-traumatic osteoarthritis model. Arthritis Res Ther. 2014; 16(6): 508-514.

10. Andriolo L, Merli G, Filardo G, Marcacci M, Kon E. Failure of autologous chondrocyte implantation. Sports Med Arthrosc Rev. 2017; 25(1): 10-8

11. Vanlauwe J, Saris DB, Victor J, Almqvist KF, Bellemans J, Luyten FP, et al. Five-year outcome of characterized chondrocyte implantation versus microfracture for symptomatic cartilage defects of the knee: early treatment matters. Am J Sports Med. 2011; 39(12): 25662574.

12. Fuchs E, Segre JA. Stem cells: a new lease on life. Cell. 2000; 100(1): 143-55.

13. Widowati W, Wijaya L, Murti H, Widyastuti H, Agustina D, Laksmitawati DR, et al. Conditioned medium from normoxia (WJMSCs-norCM) and hypoxia-treated WJMSCs (WJMSCshypoCM) in inhibiting cancer cell proliferation. Biomarkers Genomic Med. 2015; 7(1): 8-17.
14. Widowati W, Jasaputra DK, Sumitro SB, Widodo MA, Yaprianto K, Bachtiar I. Potential of unengineered and engineered wharton's jelly mesenchymal stem cells as cancer inhibitor agent. Immun Endoc Metab Agents in Med Chem. 2015; 15: 128-37.

15. Ruiz M, Cosenza S, Maumus M, Jorgensen C, Noël D. Therapeutic application of mesenchymal stem cells in osteoarthritis. Expert Opin Biol Ther. 2016; 16(1): 33-42.

16. Ayatollahi M, Talaei-Khozani T, Razmkhah M. Growth suppression effect of human mesenchymal stem cells from bone marrow, adipose tissue, and wharton's jelly of umbilical cord on PBMCs. Iran J Basic Med Sci. 2016; 19(2): 145-53.

17. Sato M, Uchida K, Nakajima H, Miyazaki T, Guerrero AR, Watanabe $\mathrm{S}$, et al. Direct transplantation of mesenchymal stem cells into the knee joints of hartley strain guinea pigs with spontaneous osteoarthritis. Arthritis Res Ther. 2012; 14(1): R31. doi: 10.1186/ ar3735.

18. Frisbie DD, Kisiday JD, Kawcak CE, Werpy NM, McIlwraith $\mathrm{CW}$. Evaluation of adipose-derived stromal vascular fraction or bone marrow-derived mesenchymal stem cells for treatment of osteoarthritis. J Orthop Res. 2009; 27(12): 1675-80.

19. Sousa EB, Casado PL, Neto VM, Duarte MEL, Aguiar DP. Synovial fluid and synovial membrane mesenchymal stem cells: latest discoveries and therapeutic perspectives. Stem Cell Res Ther. 2012; 5(5): 112. doi: 10.1186/scrt501.

20. Sugita N, Moriguchi, Y, Sakaue M, Hart DA, Yasui Y, Koizumi K, et al. Optimization of human mesenchymal stem cell isolation from synovial membrane: Implications for subsequent tissue engineering effectiveness. Regen Ther. 2016; 5: 79-85.

21. Block TJ, Marinkovic M, Tran ON, Gonzalez AO, Marshall A, Dean $\mathrm{DD}$, et al. Restoring the quantity and quality of elderly human mesenchymal stem cells for autologous cell-based therapies. Stem Cell Res Ther. 2017; 8(1): 239. doi: 10.1186/s13287-017-0688-x.

22. Widowati W, Wijaya L, Bachtiar I, Gunanegara R, Sugeng SU, Irawan YA, et al. Effect of oxygen tension on proliferation and characteristics of wharton's jelly-derived mesenchymal stem cells. Biomarkers Genomic Med. 2014; 6: 43-8.

23. Ha JW, Kim JA, Ha CW. Do the fibroblasts contained in early passage MSC population adversely affect the characteristics of stem cell population obtained from human placenta? Int J Stem Cells. 2012; 5(2): 89-95.

24. Fickert S, Fiedler J, Brenner RE. Identification, quantification and isolation of mesenchymal progenitor cells from osteoarthritic synovium by fluorescence automated cell sorting. Osteoarthritis Cartilage. 2003; 11(11): 790-800.

25. Widowati W, Murti H, Jasaputra DK, Sumitro SB, Widodo MA, Fauziah N, et al. Selective cytotoxic potential of IFN- $\gamma$ and TNF- $\alpha$ on breast cancer cell lines (T47D and MCF7). Asian J Cell Biol. 2016; 11(1): 1-12.

26. Dominici M, Le Blanc K, Mueller I, Slaper-Cortenbach I, Marini F, Krause D, et al. Minimal criteria for defining multipotent mesenchymal stromal cells. The International Society for Cellular Therapy position statement. Cytotherapy. 2006; 8 (4): 315-7.

27. Trujillo NA, Popat KC. Increased adipogenic and decreased chondrogenic differentiation of adipose derived stem cells on nanowire surfaces. Materials (Basel). 2014; 7(4): 2605-30.

28. Jin HJ, Bae YK, Kim M, Kwon SK, Jeon HB, Choi SJ, et al. Comparative analysis of human mesenchymal stem cells from bone marrow, adipose tissue, and umbilical cord blood as sources of cell therapy. Int J Mol Sci. 2013; 14(9): 17986-8001. 